\title{
METODOLOGIAS ATIVAS E O CURSO DE ADMINISTRAÇÃO: UM ESTUDO BIBLIOMÉTRICO DE 2009 A 2017
}

\author{
CURITIBA/PR MAIO/2018
}

\author{
Elizeu Barroso Alves - UNINTER - elizeu.a@uninter.com \\ Vanessa Estela Kotovicz Rolon - UNINTER - vanessa.ro@uninter.com \\ Alexsandra Petry - UNINTER - alexsandra.petry@gmail.com \\ Andressa Prado de Farias - UNINTER - defliper@gmail.com \\ Luís Carlos Dick - UNINTER - Icdick@hotmail.com \\ Thâmara Yslane Moreira de Melo - UNINTER - thamarademelo@gmail.com
}

Tipo: Investigação Científica (IC)

Natureza: Relatório Final de Pesquisa

Categoria: Métodos e Tecnologias

Setor Educacional: EDUCAÇÃO SUPERIOR

\begin{abstract}
RESUMO
O objetivo desse estudo é identificar e avaliar as publicações sobre a temática de metodologias ativas, com o foco no curso de administração, entre 2009 e 2017. Com isso, buscou-se a compreensão de como a temática é tratada por meio de um processo que visou organizar, classificar, destacar e analisar diversos aspectos do tema e de seus pesquisadores. Essa pesquisa bibliomética foi realizada nas bases da (i) Scientific Periodicals Electronic Library (SPELL); (ii) Revista Administração: Ensino e Pesquisa (RAEP); Revista da Administração Contenporânea (RAC); (iv) RAC Eletrônica; e (v) Brasilian Administration Review (BAR). As palavras-chaves utilizadas foram (a) Sala de aula invertida (b) Flipped Classroom; (c) Aprendizagem baseada em problemas; (d) Project based learning; e (e) Team based learning. Com isso, os artigos avaliados apontaram para um aumento de publicações sobre temática ocorrendo a partir da década de 2000 com os incrementos ou consolidação de políticas públicas para a educação no Brasil, e que tais estudos na área de gestão ainda está em seu estágio inicial.
\end{abstract}

Palavras-chave: Metodologias Ativas. Curso de Administração. Evolução de Estudos. ANPAD. ANGRAD.

\section{AGRADECIMENTOS}

ELIZEU BARROSO ALVES É BENEFICIÁRIO DO PROSUP-CAPES 


\section{CONSIDERAÇÕES INICIAIS}

Passado mais de 100 anos da Escola da Administração Clássica, e do ensino de gestão no Brasil - de início como ciências econômicas depois, e com grande foco na criação da Fundação Getúlio Vargas, temos o curso de administração - se faz necessário refletir quais os rumos do ensino do século XXI, século esse pautado pela revolução 4.0, pela internet das coisas, mobilidade e tecnologia.

O Curso de Administração é um dos maiores em número de alunos no Brasil, tamanha significância que, segundo o Censo da Educação Superior 2016, este curso em 2016 possuía 710.984 matrículas; 262.074 ingressantes; e 118.304 concluintes, sendo o $2^{\circ}$ maior nesse quesito, apenas atrás do curso de Direito (INEP, 2017). Segundo o Conselho Federal de Administração (CFA, 2016), a "exemplo de quase todas as outras profissões, as IES [Instituições de Ensino Superior] de natureza privada permanecem como formadoras de Administradores (82\%)".

Metodologia é considerada como os meios, regras e formas de se fazer as coisas, e nesse momento estamos de frente a um novo panorama educacional, em que se volta para o método de ensino, principalmente pela mudança do perfil dos estudantes e da tecnologia, onde há, segundo Kenski (2012), o destaque da revolução digital que está transformando o espaço educacional (HOBMEIR et al., 2017).

Assim, diante da relevância da temática de necessidade de renovação dos métodos educacionais, principalmente na educação superior, o objetivo desse estudo é identificar e avaliar as publicações sobre a temática de metodologias ativas, entre 2009 e 2017, nas revistas e banco de pesquisa das associações que discutem o curso de administração no nível de graduação e stricto sensu no Brasil, sendo elas: (i) Associação Nacional de Pós-Graduação e Pesquisa em Administração - ANPAD e (ii) Associação Nacional dos Cursos de Graduação em Administração - ANGRAD. Desta forma, esse trabalho é um estudo bibliométrico com a intenção de propor uma agenda de pesquisa.

\section{ENSINO SUPERIOR EM ADMINISTRAÇÃO NO BRASIL}

Sendo a Escola Clássica da Administração o ponta pé para se pensar gestão, sendo que o berço do ensino em Administração é nos Estados Unidos da América ainda no século XIX que em no século seguinte iria dar nascimento as Business Schools, que influenciada pela administração cientifica de Frederick Taylor (1856-1915), boa aceitação do empresariado e com base em ensino e pesquisa (OLIVEIRA; LOURENÇO; 
CASTRO, 2015). Temos que foi no início do século XX que começou a ser ofertado o curso no Brasil, como por exemplo, em 1902, quando no Rio de Janeiro na Escola Álvares Penteado e em São Paulo na Academia de Comércio iniciou-se o ensino, bem como em 1905, pelo Decreto Legislativo n. 1.339 do Governo Federal houve o reconhecimento da utilidade pública os dois cursos, validando o diploma por elas conferido (NICOLINI, 2000). No âmbito de profissionalização do ensino, temos que foi na era Vargas, que o ensino superior no Brasil é elevado a outro patamar, e tem evoluído desde então.

\section{AS METODOLOGIAS ATIVAS}

Quando abordamos o tema educação, logo pensamos em escola como um espaço físico onde, desde os tempos de outrora, tinha o seu foco na atividade do papel do professor como transmissor do conhecimento e disseminador de informações e na passividade dos alunos, onde o professor era aquele ser dotado de luz que vinha à sala de aula, iluminar os seus alunos. Todavia, se analisarmos a origem da escola como um espaço de aprendizagem, podemos verificar que a palavra escola vem do grego e significa "espaço do ócio", segundo Alves e Pretto (1999). Este formato de sala de aula, como espaço para transmitir conhecimentos e informações, perdurou até o século $X X$. Na virada para o Século XXI, abre-se um novo precedente para tentar conceber nossas formas de metodologias de ensino que saíssem dessa visão inspirada em uma teoria funcionalista. "As gerações $Y$ e $Z$ aprendem por meio de múltiplos canais de informação, utilizam várias ferramentas que otimizam o aprendizado e querem poder instrumentalizar seu ensino com a tecnologia que já utilizam para se comunicar e se relacionar com seus amigos. É uma geração que não só ouve, mas fala, critica e constrói" (TREVISANI, NETO, BACICH, 2016, p. 106). Para atender a esta nova demanda, é necessário que novas formas de ensino sejam implantados, novas metodologias.

Dessa forma, deve-se inverter a pirâmide hierárquica tradicional do conhecimento, onde as atividades consideradas de ordem superior, tais como: criar, analisar, avaliar e aplicar, que ficam no topo da pirâmide ao passo que as atividades consideradas de ordem inferior, tais como aprender e recordar, estão na base da pirâmide. Assim, o olhar para a metodologia ativa se enseja no desenvolvimento de atividades práticas em sala de aula que possibilite aos estudantes realizar análises de informações para fazer relações e possibilitar a discussão entre os alunos para que haja variadas respostas para às diversas situações, como as sociais, ambientais e econômicas.

\section{PERCURSO METEDOLÓGICO}


Gil (2009) e Triviños (1990) apontam que os estudos descritivos são aqueles que tem por intento a revelar características de um determinado assunto, e por meio de seus componentes empreendem um esforço para avalia-lo. E, esse foi o norte do percurso metodológico, com uma abordagem quantitativa, e como método, usa a pesquisa bibliométrico, pois o desígnio foi observar a evolução da literatura no decorrer dos anos (ARAUJO et al., 2000). Machado, Barbosa e Quintana (2011, p. 58): Revelar informações sobre a produção científica realizada e sobre os aspectos importantes tratados, agregando assim conhecimento que pode ser explorado tanto pelas novas publicações que almejam tratar sobre tais assuntos, quanto pelas que pretendem tratar sobre assuntos ainda não explorados.

Quadro 2: Descrição dos passos da pesquisa realizada pelos autores

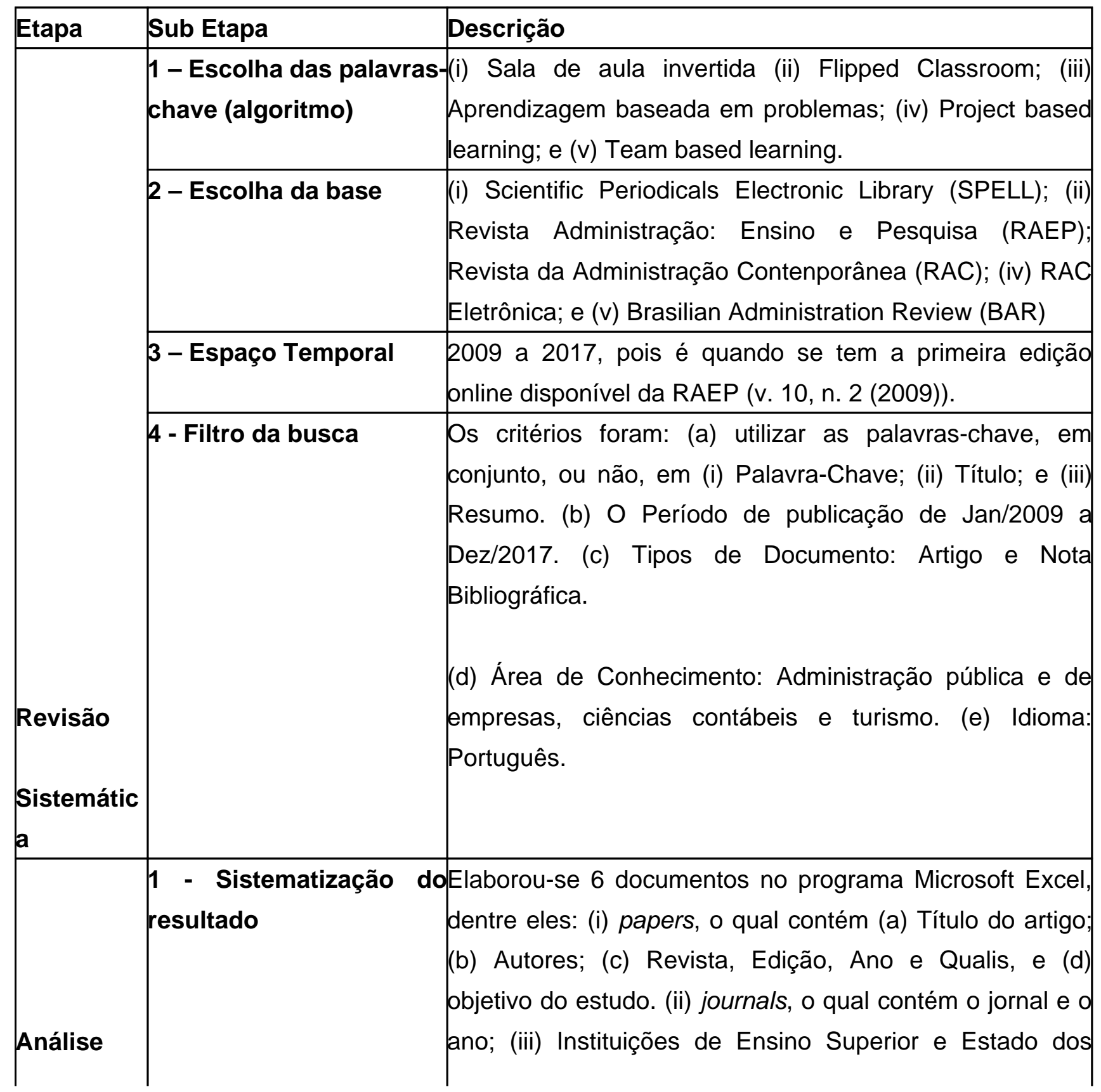




\begin{tabular}{|c|c|c|}
\hline Bibliométri & & autores. \\
\hline$c$ & $\begin{array}{l}2 \text { - Tabelas e Gráficos } \\
\text { para apresentar } \\
\text { resultados e análises }\end{array}$ & $\begin{array}{l}\text { s(a) Síntese; (b) Evolução publicação ano; (c) Quantidade } \\
\text { sde autores por artigo; (d) Qualis das revistas; (e) Titulação } \\
\text { dos autores no momento da submissão de seus artigos; (f) } \\
\text { Gênero dos autores; (g) Tabela Região das IES; (h) } \\
\text { Instituição de Ensino Superior; (i) Método utilizado nos } \\
\text { estudos; (j) Temas associativos; (k) Autores e suas } \\
\text { afiliações; e (l) tipos de fonte referências. }\end{array}$ \\
\hline
\end{tabular}

Os autores

$\mathrm{Na}$ escolha das bases de pesquisa, temos que a Spell e as Revistas RAC, RAC eletrônica e BAR tem como seus desenvolvedores a Associação Nacional de PósGraduação e Pesquisa em Administração - ANPAD que é "órgão de interação entre programas associados, grupos de pesquisa da área e a comunidade internacional" (ANPAD, s/d), ou seja, é a associação que representa o stricto sensu na área de administração. E a Revista Administração: Ensino e Pesquisa - RAEP tem como seus desenvolvedores a Associação Nacional dos Cursos de Graduação em Administração ANGRAD que: Tem se consolidado num espaço único e privilegiado para a troca de experiências acadêmicas e pedagógicas, e comprovadamente numa relevante fonte para a renovação dos conhecimentos e do aperfeiçoamento dos Cursos de Administração do País. (ANPAD, s/d). Dessa forma, a lógica foi da escolha das instituições que moldam o ensino de administração no Brasil. Não encontramos nenhum artigo em nossa pesquisa nas Revistas RAC, RAC eletrônica e BAR. Quanto ao Spell, apenas utilizando as palavras-chave, tivemos: (i) Flipped Classroom: 318 artigos; (ii) Project based learning: 292 artigos; e (iii) Team based learning: 173 artigos, assim, para a redução desses números utilizamos em conjunto, no campo assunto as palavraschave: (a) gestão e (b) administração. levantamento ocorreu de 15/03/2018 a 30/03/2018, e a tabulação e análise do dia 01/04/2018 a 06/05/2018.

\section{APRESENTAÇÃO, ANÁLISE E DISCUSSÃO DOS RESULTADOS}

\subsection{QUANTIDADE DE ARTIGOS PUBLICADOS NO PERÍODO}

Nos chama atenção o baixo número de papers com a temática, apenas os autores Rodrigo Siqueira-Batista; Romulo Siqueira-Batista; Leandro Costa Schmitz; Graziela Dias Alperstedt; Hans Michael Van Bellen; Janaina Lopes Schmitz possuem mais de 1 artigos publicados, e o elevado número de artigo de 2 a 4 autores que representam $82 \%$ dos artigos, com isso temos que há uma preferência em produção coletiva, 
principalmente dentro da mesma instituição de ensino de atuação do pesquisador. Outra informação também é que nos anos de estudo são 60 autores distintos, e se consideramos os autores com mais de uma publicação teremos 66 autores. Ademais, temos que de 2009 a 2012 havia a publicação de no máximo 2 papers por ano, e esse quadro mudou em 2014 (4 papers), em 2015 e 2016 manteve-se estável com 3 publicações por ano, e o grande salto foi em 2017 com 7 artigos. Vale ressaltar que os primeiros papers estão mais vinculados a área da saúde, sendo que há desde 20140 aumento da temática em administração. Chama também a atenção que nenhum artigo foi encontrado nas revistas Revista da Administração Contenporânea (RAC); (iv) RAC Eletrônica; e (v) Brasilian Administration Review (BAR) que são administradas pela ANPAD.

Tabela 1: Qualis das revistas

$\begin{array}{ccc}\text { Qualis } & \text { Quantidade } & \text { \% em relação ao Total } \\ \text { A2 } & 5 & 22 \% \\ \text { B1 } & 10 & 43 \% \\ \text { B2 } & 2 & 9 \% \\ \text { B3 } & 2 & 9 \% \\ \text { B4 } & 2 & 9 \% \\ \text { B5 } & 2 & 9 \% \\ \text { TOTAL } & 23 & 100 \%\end{array}$

Os autores

\subsection{PERFIL DOS AUTORES}

Para um melhor conhecimento das características desses autores, também intencionamos a identificá-los por gênero, titulação, divisão das publicações por ano, bem como os estados de origem dos autores. Assim, temos que 60 dos autores são mestres e doutores, o que explica a Qualis elevadas dos journals. E os journals que publicaram papers com especialistas e graduados foram com a Qualis B5 e B4, pois geralmente os jornauls classificado com Qualis entendida como altas, vetam esse tipo de pesquisador em suas normas de submissão.

Tabela 2: Titulação dos autores no momento da submissão de seus artigos

$\begin{array}{ccc}\text { Titulação } & \text { Número de autorias } & \% \text { em relação ao Total } \\ \text { Doutor/PhD } & 36 & 60 \%\end{array}$




$\begin{array}{ccc}\text { Mestre } & 14 & 23 \% \\ \text { Doutorando } & 3 & 5 \% \\ \text { Mestrando } & 2 & 3 \% \\ \text { Especialista } & 2 & 3 \% \\ \text { Graduado } & 3 & 5 \% \\ \text { TOTAL } & 60 & 100 \%\end{array}$

Os autores

\title{
5.3 TEMAS ASSOCIADOS A METODOLOGIAS ATIVAS
}

$\mathrm{Na}$ realização das leituras dos textos, identificamos os termos, frases e conceitos que representassem a temática geral dos papers, e essa composição gerou o quadro 4.

Quadro 4: Temas associativos

\author{
Temas associativos \\ Conhecimentos, habilidades e atitudes \\ Experiência de uso da metodologia ativa \\ Sistema educacional tradicional \\ Baseado no professor \\ Objetivo transferir o seu conhecimento \\ Novas tecnologias e metodologias
}

Perfil do estudante de administração tem mudado ao longo do tempo

Desenvolver competências múltiplas

Um desafio às aulas expositivas tradicionais

Mesmo com o apoio de recursos audiovisuais, as mesmas podem não apresentar atrativos

para esse novo perfil de discentes

Dessa forma, percebe-se que a maioria dos autores salientam a necessidade da mudança do ensino tradicional, onde a metodologia deve, nesse momento privilegiar a ação dos alunos, sendo estes os protagonistas de uma nova realidade. Os 23 artigos apresentaram em suas temáticas de Flipped Classroom, Project based learning e Team based learning no qual apresentam seus casos de aplicação do método. 
$\mathrm{Na}$ temática das referências teóricas que fomentaram os quadros teóricos dos 23 artigos da pesquisa, temos que, juntos, esses artigos utilizaram 590 obras para citação de forma geral, sem considerar os autores que mais se repetiam. E o que chama atenção é que em 75\% dos artigos existe citação das obras de Paulo Freire (1921-1997), o que justificativa uma crítica ao método tradicional. Quando se pensa em tipos de fonte referências, temos que mais de $90 \%$ são oriundas de livros e revistas, com destaque para as revistas.Os autores

Tabela 4: Tipos de fonte referências

$\begin{array}{ccc}\text { Tipo } & \text { Quantidade } & \text { \% em relação ao Total } \\ \text { Revista } & 320 & 54 \% \\ \text { Livro } & 216 & 37 \% \\ \text { Tese } & 15 & 3 \% \\ \text { Dissertação } & 9 & 2 \% \\ \text { Outros } & 30 & 5 \% \\ \text { TOTAL } & 590 & 100 \%\end{array}$

Os autores

$\mathrm{Na}$ tabela 10 o item 'outros' tem a ver com sites, resoluções e leis do Brasil, bem como notas técnicas. No quesito ano das obras, temos que nos anos 2000 contribuiu com uma imensa bagagem de referência, onde se justifica a grande movimentação de temática nessa área, pois foi a de consolidação do Fundo de Financiamento ao Estudante do Ensino Superior (FIES), criado em 1999 no Governo Fernando Henrique Cardoso (1995-2000) e ampliado pelo Governo Luiz Inácio Lula da Silva (2001-2009), bem como nesse Governo houve a criação do Programa Universidade para Todos (Prouni), e com isso houve um salto de oferta do ensino superior no Brasil. De 2011 até 2017 já temos 25\% de concentração das obras, o que indica que é um movimento de reflexão do ensino. É notório também que muitas teses geraram artigos.

\section{CONSIDERAÇÕES FINAIS}

Há um chamamento para mudança no método de ensino, e nesse estudo, que teve como objetivo fazer o levantamento das publicações sobre metodologias ativas na educação de 2009 a 2017 nos trouxe essa evidência, visto que 57\% desses artigos são a partir de 2015, tendo em 2017 surpreendente 30\% dessas publicações. Os autores vêm apresentando suas experiências, visto a gama desse tipo de artigo, e as compartilhando. Porém, nos parece que esse é um movimento de discussão do eixo Sul- 
Sudeste que detém $93 \%$ das publicações. Essa consideração ainda leva em conta que a maioria desses artigos são oriundos de pesquisadores de universidades públicas. E, com exceção de alguns autores, nos dar ares de que esse tema tem sido visto de forma individualizada, pois não há um autor célebre, ou referência nesse tipo de estudo, ao menos nos bancos a qual tivemos acesso para esse estudo. Um ponto a se considerar é que esse aumento pela temática ocorreu a partir da década de 2000 com os incrementos ou consolidação de políticas públicas para a educação no Brasil.

Dentre as revistas que foram destacadas nesse estudo, temos a RAEP concentrando $1 / 4$ das publicações sobre a temática, o que nos indica que essa é uma preocupação latente nos cursos de administração que buscam formar alunos de visão sistêmica e pronto para agir nas mais diversas situações. Levando em consideração do recorte desse estudo, podemos apresentar que tais estudos na área de gestão ainda está em seu estágio inicial, assim, abre-se uma agenda para pesquisa. Com isso, sugere-se, para estudos futuros, a possibilidade de estudos em outras bases como (i) Portal .periódicos. CAPES; (ii) SciELO; (iii) Google Scholar; (iv) EBSCO, dentre outros e até em anais eventos como (a) Encontro Nacional dos Cursos de Graduação em Administração; (b) Encontro da ANPAD e (c) Congresso Internacional ABED. Sugere-se também um olhar para as práticas desenvolvidas em outras áreas que não as ciências sociais aplicadas, bem como o olhar para essa temática em estudos de outros países com as mesmas condições

\section{BIBLIOGRAFIA}

ALVES, Lynn Rosalina Gama; PRETTO, Nelson. Escola: espaço para a produção de conhecimento. Comunicação \& Educação, n. 16, p. 29-35, 1999.

ANGRAD. Um pouco da nossa história. Disponível em: <http://www.angrad.org.br/aangrad/>. Acesso em 14 de Mar. 20186

ANPAD. Apresentação. Disponível em: <http://www.anpad.org.br/ anpad/sobre.php>. Acesso em 14 de Mar. 2018.

ARAUJO, W. T. et al. Meta-análise das dissertações do curso de mestrado ciência da informação UFPB: 1990-1999. Revista Informação e Sociedade: estudos, João Pessoa, v. 10, n. 1, p. 1-11, 2000.

CFA - Conselho Federal de Administração. Disponível em: <http://www.cfa.org.br/>. Acesso em 10 Fev. 2018. 
GIL, A. C. Métodos e técnicas de pesquisa social. 4. ed. São Paulo: Atlas, 2009.

HOBMEIR, E. C.; ALVES, E. B.; SCHNEIDER, E. I.; ROLON, V. E. K.. Blended learning na prática: uso de atividades práticas interdisciplinares como o BMG Canvas para a construção do conhecimento. In: Andreza Regina Lopes da Silva. (Org.). Demandas para a Educação a Distância no Brasil no século XXI. 1 ed. Curitiba: Atena Editora, 2017, v. 1, p. 27-28.

INEP. MEC e Inep divulgam dados do Censo da Educação Superior 2016. Disponível em: <http://portal.inep.gov.br/artigo/-/asset_publisher/B4AQV9zFY7Bv/ content/mec-e-inep-divulgam-dados-do-censo-da-educacao-superior-2016/21206>.

Acesso em 26 Mar. 2018.

KENSKI, V. M. Tecnologias e Ensino Presencial e a Distância. 9. ed. Campinas: Papirus, 2012.

MACHADO, Débora Gomes; BARBOSA, Daiane dos Santos; QUINTANA, Alexandre Costa. Análise da Produção Científica sobre os Fluxos de Caixa e a Demonstração dos Fluxos de Caixa: um estudo da Revista de Contabilidade e Finanças da Universidade de São Paulo, no período de 1989 a 2009. In: SUSTENTABILIDADE AMBIENTAL NAS ORGANIZAÇÕES, 2010, São Paulo. Anais eletrônicos. Disponível em: $<$ http://www.ea d.fea.usp.br/semead/13semead/resultado/an_resumo.asp?cod_trabalho=375>. Acesso em: 15 de Fev. de 2018.

NICOLINI, Alexandre Mendes. O ensino de graduação em administração: uma análise das Políticas Públicas Propostas. 2000. Dissertação (Mestrado em Administração) - Fundação Getúlio Vargas, São Paulo.

OLIVEIRA, Aline Lourenço; DA SILVA LOURENÇO, Cléria Donizete; DE CASTRO, Cleber Carvalho. Ensino de administração nos EUA e no Brasil: uma análise histórica. Revista Pretexto, v. 16, n. 1, p. 11-22, 2015.

TREVISANI, F.M.; NETO, A.T.; BACICH, L. Ensino Hibrido Personalização e tecnologia na educação. Porto Alegre: Penso, 2015, reimpressão 2016. 